\title{
Socioeconomic variation in injury hospitalisations in Australian children $\leq 16$ years: a 10-year population-based cohort study
}

\author{
Rebecca Seah ${ }^{1}$, Reidar P. Lystad ${ }^{1}$, Kate Curtis ${ }^{2}$ and Rebecca Mitchell ${ }^{1 *}$ (D)
}

\begin{abstract}
Background: Childhood injury remains a significant public health problem responsible for significant morbidity and mortality. However, injury has been found to increase with socioeconomic disadvantage for some injuries. The current study examines the 10-year epidemiological profile of injury hospitalisations of children $\leq 16$ years by socioeconomic status for different age group and select types of injury.

Method: A retrospective analysis of injury hospitalisations of children aged $\leq 16$ years using linked hospitalisation and mortality records during 1 July 2002 to 30 June 2012 was conducted. Negative binomial regression was used to calculate incidence rate ratios (IRRs) for injury hospitalisation rates by socioeconomic disadvantage quintile.

Results: There were 679,171 injury hospitalisations for children aged 0-16years in Australia. Children in more disadvantaged socioeconomic quintiles were more likely to be hospitalised for an injury sustained by: assault (IRR range 1.40 to 3.64), poisoning (IRR range 1.29 to 1.36), heat and hot substances (IRR range 1.07 to 1.34), and pedestrian collisions (IRR range 1.06 to 1.54) than children in advantaged socioeconomic quintiles.

Conclusions: Findings support the notion that the risk of injury hospitalisation among children differs according to socioeconomic gradient and has implications for childhood injury prevention. Policy makers should consider socioeconomic differences in the design of injury prevention measures, particularly measures directed at modifying the built environment and home-based interventions.
\end{abstract}

Keywords: Socioeconomic disadvantage, Childhood injury, Hospitalisation

\section{Background}

Globally, childhood injury is considered a substantial public health burden responsible for significant morbidity and mortality [1]. However, the burden of injury is not shared equally among all sub-populations, and generally it disproportionately affects those with a lower socioeconomic status (SES) [2]. Across several international studies, rates of injury mortality have been found to increase with socioeconomic disadvantage [35]. In comparison, studies examining the relationship between injury morbidity and SES are less consistent,

\footnotetext{
* Correspondence: r.mitchell@mq.edu.au

${ }^{1}$ Australian Institute of Health Innovation, Macquarie University, Sydney, NSW 2109, Australia

Full list of author information is available at the end of the article
}

with some reporting an inverse [4, 6], positive [7] or no relationship between SES and injury [8].

One explanation for this discrepancy may be that SES is differentially related to specific injury mechanisms [5]. The influence of socioeconomic disadvantage is not uniform across all injury types, and aggregating all injury may mask important differences [2]. For example, backyard swimming pool ownership and access to different types of recreational activities increases with more advantaged SES. Thus, the likelihood of sustaining an injury from a pool drowning and/or recreational activity would increase with individuals of a higher SES [9]. Conversely, pedestrian and/or motor vehicle collisions tend to be higher among those residing in lower SES communities, where the population density is higher 
and public safety measures such as safer road infrastructures may be lacking $[10,11]$.

The risk of unintentional and intentional injury also varies with age. For intentional injury, self-harm-related behaviours are noticeably higher in older children aged 12 to 16, [12, 13]. Conversely, hospitalisations due to burns, unintentional poisoning and drowning in the home occur more frequently in younger children under the age of seven [14]. To date, population-based studies focusing on the role of SES and risk of injury hospitalisations of children in Australia have been scarce. Given that socioeconomic disadvantage is a fundamental determinant of ill-health, an examination of its relationship with injury would inform prevention interventions based on socioeconomic gradient and injury type. The current study aims to examine the 10-year epidemiological profile of injury hospitalisations of children $\leq 16$ years by SES for different age groups and select types of injury.

\section{Method}

A retrospective analysis of injury hospitalisations for children aged $\leq 16$ years using linked hospitalisation and mortality records during 1 July 2002 to 30 June 2012 was conducted. The method to obtain the hospitalisation and mortality data and to identify the injury hospitalisations has been described elsewhere [15] and is summarised here.

\section{Hospitalisation and mortality data}

Hospitalisation information was obtained from the National Hospital Morbidity database and jurisdiction-based hospitalisation data collections in Australia. Data was available from all Australian states and territories, however in the Australian Capital Territory data were only available from 1 July 2004. Hospitalisation data includes information on patient demographics, source of referral, diagnoses, external cause, type of hospital separation (e.g. discharged, death), and place of occurrence. Diagnoses and external cause codes were classified using the International Classification of Diseases, 10th Revision, Australian Modification (ICD-10-AM) [16]. Injury admissions were identified using a principal diagnosis classification of injury (ICD-10-AM: S00-T78).

Hospitalisation and mortality records were probabilistically linked by the Australian Institute of Health and Welfare to enable identification of deaths after hospital discharge. Hospitalisation and mortality records for Western Australia were linked by the Western Australian Data Linkage Branch. The Tasmanian hospitalisation records were linked using a unique patient identifier, with mortality post-admissions recorded within Tasmanian hospitalisation data. In Victoria, 20.4\% $(n=41,482)$ of the child injury hospital records were not able to be linked and included in the study due to incompleteness in the linkage variables, such as name and residential address.

\section{Identification of health conditions and injury severity}

Chronic health conditions which are common among children (e.g., diabetes, asthma, cancer, obesity, cystic fibrosis) were identified within the hospitalisation data $[17,18]$. A chronic health condition was defined as lasting up to $\geq 12$ months, and placing a limitation on an individual's ability for self-care, independent living, social interactions, and/or resulted in the need for ongoing healthcare service use [19]. Chronic health conditions were categorised as none, one, or two or more health conditions.

Injury severity was estimated using the International Classification of Disease Injury Severity Score (ICISS) by applying existing survival risk ratios (SRR) to injury diagnoses classifications in the hospitalisation data [20]. The ICISS was derived for each individual by multiplying the probability of survival for each injury diagnosis using SRRs derived for each injury diagnosis [20]. Three severity levels were used to define minor $(\geq 0.99)$, such as concussive injury or fracture of the lower end of the humerus, moderate $(>0.941-<0.99)$, such as fracture of the shoulder/upper arm or contusion of the abdominal wall, and serious $(\leq 0.941)$, such as traumatic brain injury or fracture of the cervical vertebra [21].

\section{Identification of socioeconomic disadvantage}

A measure of socioeconomic disadvantage for each hospitalisation was assigned to the child's postcode of usual residence using the Index of Relative Socioeconomic Disadvantage (IRSD) [22]. The IRSD is an index of socioeconomic disadvantage, where lower scores indicate more disadvantaged areas. The IRSD's quintiles are derived every five years from Australia's population census using characteristics such as income, education, employment, occupation and other measures that indicate socioeconomic advantage (e.g., high income, tertiary education) and disadvantage (e.g., unemployment, low number of bedrooms in home). There were 7238 (1.1\%) child injury hospitalisations where the IRSD was not available that were excluded from analyses.

\section{Data management and analyses}

All statistical analyses were performed using SAS version 9.4 [23]. All hospital episodes of care related to the one injury event were linked to form a period of care. Denominator data for the number of children aged $\leq 16$ years were obtained from the Australian Bureau of Statistics population estimates for each jurisdiction by IRSD [24]. Direct age-standardised incidence rates were calculated using the recommended Australian residential population at 30 June 2001 as the standard population $[25,26]$. Due to changes in statistical area partitioning for IRSD quintiles in 2009, temporal trends for age-standardised hospitalisation rates were not statistically examined [27]. Thirty-day mortality 
was calculated from the date of admission of the index injury hospitalisation. Negative binomial regression analyses were used to calculate incidence rate ratios (IRRs) for injury hospitalisation rates by socioeconomic disadvantage quintile. The main explanatory variable in the models was the socioeconomic disadvantage quintiles, with age and sex entered as covariates and the log of the population as an offset.

\section{Results}

Over the ten-year study period, there were 679,171 injury hospitalisations for children aged $\leq 16$ years in Australia.

\section{Injury hospitalisation rates}

The rates of injury hospitalisations remained relatively stable across each quintile between 2002 to 2008. Between 2008 and 2010, there was an increase in rates of injury hospitalisations for the most socioeconomically disadvantaged quintile, before declining between 2009 to 2011 (Fig. 1).

\section{Demographic and injury characteristics}

Overall, males accounted for around two-thirds of injury hospitalisations. Children aged 11-16 years accounted for one in five hospitalised injuries across all SES disadvantage quintiles, while children living in the most disadvantaged SES quintile had the highest proportion of injury hospitalisations for serious injuries (8.2\%). Thirty-day mortality was relatively similar for children living in each SES quintile (Table 1).

\section{Injury mechanism}

Fall-related injuries, and injury due to inanimate mechanical forces (such as being struck by an object) accounted for the highest proportion of child hospitalisations across each SES quintile. Child hospitalisations due to assault and poisoning injuries were highest for children living in the most disadvantaged SES quintile (Table 2).

\section{Adjusted incidence rate ratios}

Children living in a more disadvantaged SES quintile were more likely to be hospitalised for an injury sustained by assault (IRR range 1.40 to 3.64), poisoning (IRR range 1.29 to 1.36), heat and hot substances (IRR range 1.07 to 1.34), and pedestrian collisions (IRR range 1.06 to 1.54 ) compared to children living in the least disadvantaged quintile (Table 3 ). The remaining injury mechanisms (i.e. pedal cyclists, falls, self-harm for 1116 years), along with injuries that occurred in the home and farm, and injuries due to sports and leisure activities showed inconsistent relationships between SES disadvantage and injury. Overall, children in more disadvantaged SES quintiles were more likely to be hospitalised for a moderate or serious injury compared to the least disadvantaged quintile (Table 4).

\section{Discussion}

This study identified that the incidence of injury hospitalisations due to pedestrian collisions, assault, poisoning, and heat and hot substances increased with SES disadvantage.

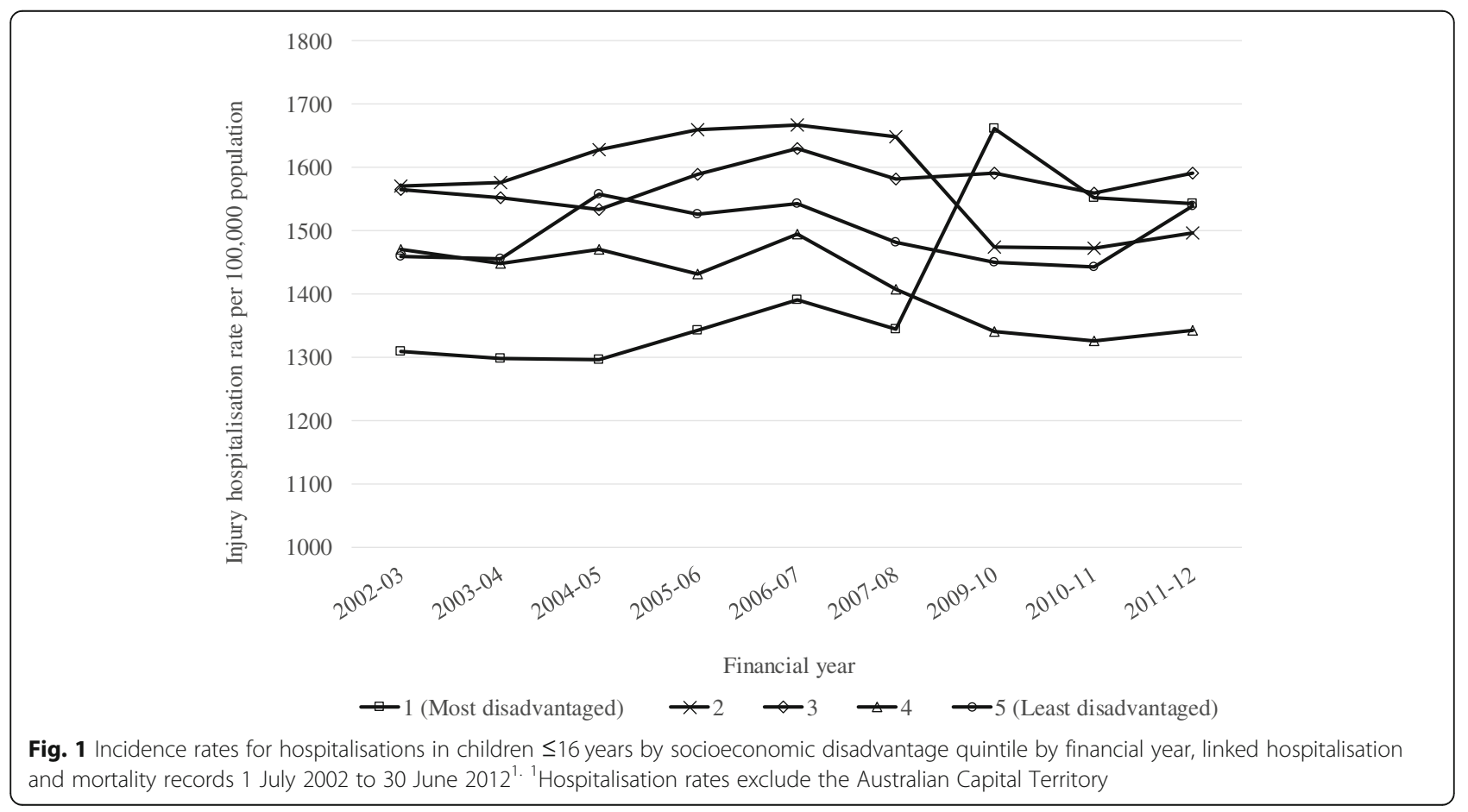


Table 1 Demographic characteristics injury-related hospitalisations by socioeconomic disadvantage quintile, linked Australian hospitalisation and mortality records, 1 July 2002 to 30 June 2012

\begin{tabular}{|c|c|c|c|c|c|c|c|c|c|c|}
\hline & \multicolumn{2}{|c|}{$\begin{array}{l}\text { Most disadvantaged } \\
(\mathrm{n}=133,397)\end{array}$} & \multicolumn{2}{|c|}{$2(n=141,812)$} & \multicolumn{2}{|c|}{$3(n=141,876)$} & \multicolumn{2}{|c|}{$4(n=126,287)$} & \multicolumn{2}{|c|}{$\begin{array}{l}\text { Least Disadvantaged } \\
(n=135,799)\end{array}$} \\
\hline & $n$ & $\%$ & $n$ & $\%$ & $n$ & $\%$ & $\mathrm{n}$ & $\%$ & $n$ & $\%$ \\
\hline \multicolumn{11}{|l|}{ Gender $^{a}$} \\
\hline Male & 84,434 & 63.3 & 90,659 & 63.9 & 90,921 & 64.1 & 80,132 & 63.5 & 86,239 & 63.5 \\
\hline Female & 48,960 & 36.7 & 51,151 & 36.1 & 50,954 & 35.9 & 46,154 & 36.5 & 49,559 & 36.5 \\
\hline \multicolumn{11}{|l|}{ Age groups ${ }^{b}$} \\
\hline $0-5$ & 47,550 & 35.6 & 46,438 & 32.7 & 47,480 & 33.4 & 44,589 & 35.3 & 46,928 & 34.6 \\
\hline $6-10$ & 32,312 & 24.2 & 34,770 & 24.5 & 34,770 & 24.5 & 31,252 & 24.7 & 34,662 & 25.5 \\
\hline $11-16$ & 53,535 & 40.1 & 60,379 & 42.6 & 59,626 & 42.0 & 50,446 & 39.9 & 54,209 & 39.9 \\
\hline \multicolumn{11}{|l|}{ Health conditions } \\
\hline None & 126,426 & 94.8 & 134,000 & 94.5 & 134,306 & 94.7 & 119,913 & 95.0 & 128,628 & 94.7 \\
\hline One & 5924 & 4.4 & 6554 & 4.6 & 6413 & 4.5 & 5470 & 4.3 & 6235 & 4.6 \\
\hline Two or more & 1047 & 0.8 & 1258 & 0.9 & 1157 & 0.8 & 904 & 0.7 & 936 & 0.7 \\
\hline \multicolumn{11}{|l|}{ Injury severity } \\
\hline Minor & 77,636 & 58.2 & 85,549 & 60.3 & 87,132 & 61.4 & 78,630 & 62.3 & 87,158 & 64.2 \\
\hline Moderate & 44,766 & 33.6 & 45,974 & 32.4 & 45,078 & 31.8 & 39,361 & 31.2 & 40,935 & 30.1 \\
\hline Serious & 10,995 & 8.2 & 10,289 & 7.3 & 9666 & 6.8 & 8296 & 6.6 & 7706 & 5.7 \\
\hline 30-day mortality & 250 & 0.2 & 228 & 0.2 & 189 & 0.1 & 169 & 0.1 & 127 & 0.1 \\
\hline
\end{tabular}

anformation on gender was not known for 8 hospitalisations. ${ }^{b}$ Information on age for one hospitalisation was missing

These findings are consistent with the broader context of SES disadvantage as a primary risk factor for paediatric injuries [28, 29]. For example, children in the United Kingdom who resided in more deprived areas were up to four times more likely to be injured from a pedestrian incident than children in lesser deprived areas, with similar findings reflected in the United States, Canada and Sweden [28].

Relative SES disadvantage had the strongest relationship with assault-related injuries in the current study. Assault-related injury in all ages has been consistently found to be positively related to deprived populations, where poverty and income inequality tends to be higher [30]. However, for other intentional injury hospitalisations such as self-harm, there was an inconsistent relationship with SES disadvantage among 11-16 year olds, which directly contrasts with previous research where the role of SES deprivation using both individual (e.g., low parental education and household income) and area-based indicators were positively associated with risk of self-harm in adolescents [31, 32].

Children in more disadvantaged SES quintiles were found to be at a higher risk of poisoning, particularly those aged $0-5$ years. Similarly, a Canadian study identified that children living in the most socioeconomically disadvantaged area in Quebec had a 68\% increased risk of poisoning compared to children living in the least socioeconomically disadvantaged area [33]. Likewise, an increased risk of poisoning among 0-4 year olds was found with increasing social deprivation in England [34].

Despite accounting for the highest proportion of injury hospitalisations, fall injury hospitalisations did not show a consistent relationship with SES disadvantage. This study supports findings from a Swedish study which found no association between material deprivation, SES and falls [35]. Other area-based studies examining the role of SES and childhood falls have also showed mixed findings, with rates of hospitalisation dependent on the diagnoses and type of fall [33]. For instance, an examination of child injury hospitalisations across the SES gradient indicated that differences in rates only reached significance for falls from a low height [33].

In terms of child injury prevention, adverse home and neighbourhood structural conditions can elevate the risk of other forms of childhood injury. For example, children residing in more socioeconomically disadvantaged areas often live in older homes, have limited safe spaces and increased exposure to traffic, all of which elevate their risk of poisoning, burns and pedestrian injuries [36, 37]. Moreover, adverse home and neighbourhood structures are also marked with low social cohesion, increased crime rates and poverty, which may explain the consistent pattern between high SES disadvantage and increased assault-related injury risk [38].

The causal mechanisms underlying the SES differences in childhood injury are complex and multi-factorial. The 
Table 2 Injury mechanism for injury-related hospitalisations by socioeconomic disadvantage quintile, linked Australian hospitalisation and mortality records, 1 July 2002 to 30 June 2012

\begin{tabular}{|c|c|c|c|c|c|c|c|c|c|c|}
\hline & \multicolumn{2}{|c|}{$\begin{array}{l}\text { Most disadvantaged } \\
(n=133,397)\end{array}$} & \multicolumn{2}{|c|}{$\begin{array}{l}2 \\
(n=141,812)\end{array}$} & \multicolumn{2}{|c|}{$\begin{array}{l}3 \\
(n=141,876)\end{array}$} & \multicolumn{2}{|c|}{$\begin{array}{l}4 \\
(n=126,287)\end{array}$} & \multicolumn{2}{|c|}{$\begin{array}{l}\text { Least Disadvantagec } \\
(\mathrm{n}=135,799)\end{array}$} \\
\hline & $\mathrm{n}$ & $\%$ & $\mathrm{n}$ & $\%$ & $n$ & $\%$ & $\mathrm{n}$ & $\%$ & $\mathrm{n}$ & $\%$ \\
\hline Road transport & 19,309 & 14.3 & 21,971 & 15.0 & 20,705 & 14.3 & 16,527 & 13.1 & 14,188 & 10.4 \\
\hline Pedestrian & 1919 & 1.4 & 1626 & 1.1 & 1559 & 1.1 & 1284 & 1.0 & 1263 & 0.9 \\
\hline Pedal cyclist & 6706 & 5.0 & 8160 & 5.6 & 8142 & 5.6 & 6883 & 5.5 & 7236 & 5.3 \\
\hline Motorcyclist & 4459 & 3.3 & 5693 & 3.9 & 5268 & 3.6 & 3814 & 3.0 & 2276 & 1.7 \\
\hline Motor vehicle occupant ${ }^{a}$ & 3763 & 2.8 & 3382 & 2.3 & 3030 & 2.1 & 2441 & 1.9 & 1870 & 1.4 \\
\hline Other land transport & 2462 & 1.8 & 3110 & 2.1 & 2706 & 1.9 & 2105 & 1.7 & 1543 & 1.1 \\
\hline Water, air and other and unspecified transport & 412 & 0.3 & 510 & 0.4 & 500 & 0.3 & 500 & 0.4 & 580 & 0.4 \\
\hline Falls & 46,662 & 34.9 & 51,905 & 36.6 & 54,332 & 38.3 & 50,711 & 40.2 & 57,263 & 42.2 \\
\hline Inanimate mechanical forces & 24,392 & 18.3 & 24,682 & 17.0 & 25,344 & 17.5 & 22,125 & 17.5 & 23,144 & 17.0 \\
\hline Animate mechanical forces & 7637 & 5.7 & 7637 & 5.3 & 8239 & 5.7 & 7213 & 5.71 & 7293 & 5.4 \\
\hline Drowning and submersion & 583 & 0.4 & 583 & 0.4 & 532 & 0.4 & 534 & 0.4 & 512 & 0.4 \\
\hline Other threats to breathing & 529 & 0.4 & 519 & 0.4 & 517 & 0.4 & 506 & 0.4 & 463 & 0.3 \\
\hline $\begin{array}{l}\text { Electric current, radiation, extreme ambient air } \\
\text { temperature and pressure }\end{array}$ & 160 & 0.2 & 178 & 0.1 & 168 & 0.1 & 110 & 0.1 & 104 & 0.1 \\
\hline Smoke, fire and flames & 1393 & 1.0 & 1026 & 0.7 & 867 & 0.6 & 674 & 0.5 & 480 & 0.4 \\
\hline Heat and hot substances & 4225 & 3.2 & 3713 & 2.6 & 3083 & 2.1 & 3095 & 2.5 & 2905 & 2.1 \\
\hline Venomous animals and plants & 1634 & 1.2 & 1727 & 1.2 & 1341 & 0.9 & 963 & 0.8 & 1029 & 0.8 \\
\hline Poisoning & 5869 & 4.4 & 5470 & 3.8 & 5292 & 3.7 & 4485 & 3.6 & 4101 & 3.0 \\
\hline Intentional self-harm & 3701 & 2.8 & 4067 & 2.8 & 3731 & 2.6 & 3174 & 2.5 & 3378 & 2.5 \\
\hline Assault & 4399 & 3.3 & 3007 & 2.1 & 2643 & 1.8 & 1936 & 1.5 & 1535 & 1.1 \\
\hline Other and unspecified injury mechanism & 12,492 & 9.4 & 14,264 & 9.9 & 14,582 & 10.1 & 13,734 & 10.9 & 18,824 & 13.9 \\
\hline
\end{tabular}

ancludes heavy vehicle and bus occupants

current findings support the influence of SES inequality on child injury morbidity for some types of injuries [39]. Designing interventions to target risk and protective factors of injuries is an important challenge for policy makers to reduce the burden of childhood injury among socioeconomically disadvantaged groups. Isolated or region specific interventions, such as parental education and home visitations for at risk mothers, have demonstrated positive short-term outcomes of reduced injuries among infants [40]. Improving medical literacy and provision of safety equipment has been shown to improve poison prevention practices, however, the impact of such interventions, while promising, is currently unclear [41]. Scald and burn prevention has had positive results through the installation of hot water regulating devices and smoke alarms [37].

While encouraging behavioural modifications through community-based prevention programmes is highly favoured, these are not always effective for certain injuries, such as burns and pedestrian collisions [37, 42]. Compared to interventions focusing on individual behaviour change, interventions at a community-level focusing on both environmental and individual factors, such as safer housing designs in public or low-income housing, redesigning roads through installing speed bumps and reducing road hazards to allow safer crossing may be a more effective injury prevention strategy [5, $39,43]$. However, early intervention programs that target high risk and/or violent behaviour among youth remain an important challenge for policy makers to reduce the burden of intentional injuries.

The current study has several limitations. Due to changes in statistical area portioning of quintiles, trends of hospitalisation injury by SES quintile were unable to be estimated [27], and it is most likely that the sudden increase in injury hospitalisation rates between 2007 and 08 and 2009-10 for SES quintiles 1 and 2 reflects this change. There was an under-enumeration of total injury hospitalisations as there was no information on injury hospitalisations in the Australian Capital Territory prior to 1 July 2004 and up to 3975 injury hospitalisations each year in Victoria were unable to be linked. The present study relies on an area-based indicator of SES disadvantage, and may be subject to ecological fallacy [44]. As the IRSD summarises the characteristics of people and households within a geographical area, it 
Table 3 Adjusted incidence rate ratios for injury-related hospitalisations by quintile of socioeconomic disadvantage for select injury mechanisms, linked Australian hospitalisation and mortality records, 1 July 2002 to 30 June $2012^{\mathrm{a}}$

\begin{tabular}{l} 
Select injury mechanisms \\
\hline Pedestrian \\
Most disadvantaged quintile \\
2nd \\
3rd \\
4th \\
Least disadvantaged quintile \\
Pedal cycle \\
Most disadvantaged quintile \\
2nd \\
3rd \\
4th \\
Least disadvantaged quintile \\
Falls \\
Most disadvantaged quintile \\
2nd \\
3rd \\
4th
\end{tabular}

Least disadvantaged quintile Drowning - all ages

Most disadvantaged quintile 2nd

$3 r d$

4th

Least disadvantaged quintile

Drowning (0-5 years)

Most disadvantaged quintile

2nd

$3 r d$

4th

Least disadvantaged quintile

Heat and other hot substances - all ages

Most disadvantaged quintile

2nd

$3 r d$

4th

Least disadvantaged quintile

Heat and other hot substances ( $0-5$ years)

Most disadvantaged quintile

2nd

$3 r d$

4th

Least disadvantaged quintile

$\operatorname{IRR}^{\mathrm{b}}(95 \% \mathrm{Cl})$

$.54(1.40 \text { to } 1.69)^{* * *}$

$1.37(1.24 \text { to } 1.50)^{* * *}$

$1.30(1.18 \text { to } 1.43)^{* * *}$

$1.06(0.97 \text { to } 1.18)^{* * * *}$

1.00

0.91 (0.80 to 1.04$)$

$1.13(1.0$ to 1.28$)$

$1.14(1.00 \text { to } 1.30)^{*}$

0.96 (0.84 to 1.09$)$

1.00

$0.81(0.75 \text { to } 0.88)^{* * *}$

0.96 (0.88 to 1.04$)$

0.99 (0.92 to 1.07$)$

$0.92(0.85 \text { to } 1.00)^{*}$

1.00

$1.10(0.96$ to 1.25$)$

$1.22(1.07 \text { to } 1.39)^{*}$

1.07 (0.94 to 1.22$)$

1.06 (0.93 to 1.22$)$

1.00

$1.08(0.75$ to 1.55$)$

1.24 (0.86 to 1.78$)$

$1.13(0.78$ to 1.63$)$

$1.13(0.78$ to 1.63$)$

1.00

$1.34(1.23 \text { to } 1.46)^{* * *}$

$1.33(1.22 \text { to } 1.45)^{* * *}$

$1.07(0.98$ to 1.17$)$

$1.11(1.01 \text { to } 1.21)^{*}$

1.00

1.38 (0.99 to 1.92$)$

1.30 (0.94 to 1.81$)$

1.07 (0.77 to 1.50$)$

1.09 (0.78 to 1.51$)$

1.00
Table 3 Adjusted incidence rate ratios for injury-related hospitalisations by quintile of socioeconomic disadvantage for select injury mechanisms, linked Australian hospitalisation and mortality records, 1 July 2002 to 30 June 2012a (Continued)

\begin{tabular}{ll}
\hline Select injury mechanisms & IRR $^{\mathrm{b}}(95 \% \mathrm{Cl})$ \\
\hline Poisoning - all ages & \\
Most disadvantaged quintile & $1.41(1.25 \text { to } 1.59)^{* * *}$ \\
2nd & $1.33(1.18 \text { to } 1.50)^{* * *}$ \\
3rd & $1.29(1.14 \text { to } 1.45)^{* * *}$ \\
4th & $1.11(0.98$ to 1.25$)$ \\
Least disadvantaged quintile & 1.00 \\
Poison (0-5 years) & \\
Most disadvantaged quintile & $1.36(0.95$ to 1.95$)$ \\
2nd & $1.33(1.18 \text { to } 1.50)^{* * *}$ \\
3rd & $1.29(1.14 \text { to } 1.45)^{* * *}$ \\
4th & $1.11(0.98$ to 1.25$)$ \\
Least disadvantaged quintile & 1.00 \\
Self-harm (11-16years) & \\
Most disadvantaged quintile & $0.92(0.59$ to 1.42$)$ \\
2nd & $1.16(0.73$ to 1.82$)$ \\
3rd & $1.19(0.75$ to 1.90$)$ \\
4th & $1.05(0.66$ to 1.68$)$ \\
Least disadvantaged quintile & 1.00
\end{tabular}

Assault

Most disadvantaged quintile

$3.64(3.16 \text { to } 4.19)^{* * *}$

2nd

$3 r d$

$2.46(2.13 \text { to } 2.84)^{* * *}$

$2.06(1.79 \text { to } 2.38)^{* * * *}$

4th

Least disadvantaged quintile

$1.40(1.20 \text { to } 1.62)^{* * *}$

1.00

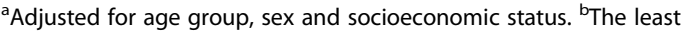
disadvantaged quintile was used as the reference group for all variables. ${ }^{*} p<$ $0.5,{ }^{* *} p<0.001,{ }^{* * *} p<0.0001$

does not reflect individual differences or specific households (e.g. low income does not always equate to disadvantage, as certain low-income households may have access to different social and economic resources that could help them mitigate their risk of childhood injury). Nonetheless, area-based classifications have been shown to correlate strongly with individual-level SES [45], and other studies have also found that area-based measures of SES disadvantage are associated with risk of childhood injury, independent of individual-level SES [45, 46]. It is possible that there is variation in the use of hospital services for children from different SES backgrounds; for example individuals may choose to use other available medical services to treat minor injury. Further research is needed to examine the type of health services used by injured children from different SES backgrounds. 
Table 4 Adjusted incidence rate ratios for injury-related hospitalisations by quintile of socioeconomic disadvantage for select place of occurrence, activity at time of injury and injury severity, linked Australian hospitalisation and mortality records, 1 July 2002 to 30 June $2012^{a}$

\begin{tabular}{ll}
\hline $\begin{array}{l}\text { Select activity at time of injury, } \\
\text { place of occurrence, and injury severity }\end{array}$ & $\operatorname{IRR}^{\mathrm{b}}(95 \% \mathrm{Cl})$ \\
\hline Activity at time of injury & \\
Sport and leisure & \\
Most disadvantaged quintile & $0.80(0.66 \text { to } 0.96)^{*}$ \\
2nd & $0.92(0.78$ to 1.12$)$ \\
3rd & $0.99(0.82$ to 1.20$)$ \\
4th & $0.98(0.81$ to 1.18$)$ \\
Least disadvantaged quintile & 1.00
\end{tabular}

Place of occurrence

Home

Most disadvantaged quintile
2nd
3rd
4th

Least disadvantaged quintile Farm

Most disadvantaged quintile
2nd
3rd
4th

Least disadvantaged quintile Injury Severity

Minor (ICISS $\geq 0.99$ )

$\begin{array}{ll}\text { Most disadvantaged quintile } & 0.89(0.84 \text { to } 0.94)^{* * *} \\ \text { 2nd } & 1.03(0.97 \text { to } 1.08) \\ \text { 3rd } & 1.04(0.99 \text { to } 1.09) \\ \text { 4th } & 0.94(0.89 \text { to } 0.99)^{*} \\ \text { Least disadvantaged quintile } & 1.00 \\ \text { Moderate (ICISS }>0.941-<0.99) & \\ \text { Most disadvantaged quintile } & 1.09(1.03 \text { to } 1.15)^{*} \\ \text { 2nd } & 1.17(1.11 \text { to } 1.23)^{* * *} \\ \text { 3rd } & 1.14(1.08 \text { to } 1.20)^{* * *} \\ \text { 4th } & 0.99(0.94 \text { to } 1.05) \\ \text { Least disadvantaged quintile } & 1.00 \\ \text { Serious (ICISS } \leq 0.941) & \\ \text { Most disadvantaged quintile } & 1.43(1.33 \text { to } 1.54)^{* * *} \\ \text { 2nd } & 1.40(1.31 \text { to } 1.51)^{* * *} \\ \text { 3rd } & 1.31(1.22 \text { to } 1.41)^{* * *} \\ \text { 4th } & 1.13(1.05 \text { to } 1.21)^{*} \\ \text { Least disadvantaged quintile } & \end{array}$

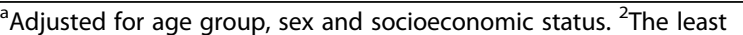
disadvantaged quintile was used as the reference group for all variables. ${ }^{*} p<0.5,{ }^{* *} p<0.001,{ }^{* * *} p<0.0001$

\section{Conclusions}

This is the first population-based epidemiological study examining hospitalised injury and SES disadvantage in Australian children over a 10-year period. The findings support the notion that the risk of hospitalisations from certain injury mechanisms, such as assault and pedestrian incidents, differs for children according to SES gradient. A national injury prevention strategy implementing interventions directed at modifying the built environment in conjunction with community and home interventions, will function as a way toward reducing childhood injury morbidity.

\section{Abbreviations}

ICD-10-AM: International Classification of Diseases, 10th Revision, Australian Modification; ICISS: International Classification of Disease Injury Severity Score; IRR: Incidence rate ratio; IRSD: Index of relative socioeconomic disadvantage; SES: Socioeconomic status; SRR: Survival risk ratio

$1.16(1.11 \text { to } 1.22)^{* * *}$
$1.28(1.22 \text { to } 1.34)^{* * *}$
$1.18(1.12 \text { to } 1.23)^{* * *}$
$1.06(1.01 \text { to } 1.11)^{*}$
1.00

$3.64(3.18 \text { to } 4.18)^{* * *}$ $4.76(4.17 \text { to } 5.44)^{* * *}$ $3.69(3.23 \text { to } 4.23)^{* * *}$ $1.92(1.66 \text { to } 2.22)^{* * *}$ 1.00

\section{Acknowledgements}

The authors wish to thank the State and Territory Departments of Health for providing access to their admitted patient data collections, the Australian Institute of Health and Welfare for providing access to the National Hospital Morbidity Database and the National Death Index, and Australian Institute of Health and Welfare Data Linkage Unit for conducting the record linkage. Cause of Death Unit Record File data are provided to the Australian Institute of Health and Welfare by the Registries of Births, Deaths and Marriages and the National Coronial Information System and include cause of death coded by the Australian Bureau of Statistics. The authors would also like to thank the Western Australian Registry of Births, Deaths and Marriages for providing access to Western Australian mortality data and the Western Australian Data Linkage Branch for conducting the data linkage of child injury

hospitalisations and mortality data collections in Western Australia.

\section{Funding}

This research was funded by the Day of Difference Foundation. RM was supported by a career fellowship from the New South Wales Ministry of Health under the New South Wales Health Early-Mid Career Fellowships Scheme. The funding bodies had no role in the design and/or conduct of the study, in the data analysis, interpretation of the data or the writing of the manuscript.

\section{Availability of data and materials}

The data that support the findings of this study are available from each state and territory health department in Australia and the National Death Index but restrictions apply to the availability of these data, which were used under license for the current study, and so are not publicly available. Data are however available from the authors upon reasonable request and with permission of all data custodians and all ethics committees.

\section{Authors' contributions}

RM developed the study design, acquired the data, and conducted the analysis. RS drafted the manuscript. All authors (RM, RS, RL and KC) were involved in interpretation and critical revision of the manuscript. All authors have read and approved the final version of the manuscript.

\section{Ethics approval and consent to participate}

Ethical approval was obtained from eight jurisdiction-based health ethics committees (i.e. the New South Wales Population Health Services Research Ethics Committee (2013/07/466), the Australian Capital Territory Health Human Research Ethics Committee (HREC) (ETH.7.13.149), the Western Australian Health HREC (2014/09), the South Australian Health HREC (HREC/13/SAH/ 61), the Northern Territory Menzies School of Health Research HREC (HREC2013-2048), the University of Tasmania HREC (H0013335), the Victorian Health Department HREC (19/13), the Queensland Health Department HREC (HREC) 15/QRHC/20), and the Australian Institute of Health and Welfare (EO2013/4/ 66). A waiver of consent was granted by the ethics committees. 


\section{Consent for publication}

Not applicable.

\section{Competing interests}

The authors declare that they have no competing interests.

\section{Publisher's Note}

Springer Nature remains neutral with regard to jurisdictional claims in published maps and institutional affiliations.

\section{Author details}

${ }^{1}$ Australian Institute of Health Innovation, Macquarie University, Sydney, NSW 2109, Australia. ${ }^{2}$ Sydney Medical School, University of Sydney, Sydney, Australia.

Received: 16 August 2018 Accepted: 21 November 2018

Published online: 04 December 2018

\section{References}

1. World Health Organization. World report on child injury prevention. Geneva: World Health Organization; 2008.

2. Poulos R, Hayen A, Finch C, Zwi A. Area socioeconomic status and childhood injury morbidity in New South Wales, Australia. Injury prevention. 2007:13:322-7.

3. Shaw C, Blakley T, Crampton P, Atkinson J. The contribution of causes of death to socioeconomic inequalities in child mortality: New Zealand 19811999. The New Zealand Medical Journal. 2005;118(1227):U1779.

4. Bronwell M, Frieson D, Mayer T. Childhood injury rates in Manitoba: socioeconomic influences. Canadian Journal of Public Health. 2002;93:S50S6.

5. Cubbin C, LeClere FB, Smith GS. Socioeconomic status and the occurrence of fatal and nonfatal injury in the United States. Am J Public Health. 2000; 90(1):70-7.

6. Lyons RA, Jones SJ, Deacon T, Heaven M. Socioeconomic variation in injury in children and older people: a population based study. Injury Prevention. 2003;9(1):33

7. Lalloo R, Sheiham A. Risk factors for childhood major and minor head and other injuries in a nationally representative sample. Injury. 2003;34(4):261-6.

8. Williams JM, Currie CE, Wright P, Elton RA, Beattie TF. Socioeconomic status and adolescent injuries. Soc Sci Med. 1997:44(12):1881-91.

9. $\mathrm{Ni} \mathrm{H}$, Barnes $\mathrm{P}$, Hardy AM. Recreational injury and its relation to socioeconomic status among school aged children in the US. Injury Prevention. 2002;8(1):60.

10. Pomerantz WJ, Dowd MD, Buncher CR. Relationship between socioeconomic factors and severe childhood injuries. J Urban Health. 2001; 78(1):141-51.

11. LaScala EA, Gruenewald PJ, Johnson FW. An ecological study of the locations of schools and child pedestrian injury collisions. Accid Anal Prev. 2004;36(4):569-76.

12. Hawton K, Saunders K, Topiwala A, Haw C. Psychiatric disorders in patients presenting to hospital following self-harm: a systematic review. J Affect Disord. 2013;151:821-30

13. Mitchell $\mathrm{R}$, Seah $\mathrm{R}$, Ting $H$, Curtis $K$, Foster $\mathrm{K}$. Intentional self-harm and assault hospitalisations and treatment cost of children in Australia over a 10-year period. Aust N Z J Public Health. 2018:42(3):240-6.

14. Balseven-Odabasi A, Tumer A, Keten A, Yorganci K. Burn injuries among children aged up to seven years. Turk J Pediatr. 2009;51(328-325).

15. Mitchell R, Curtis K, Forster K. A 10-year review of child injury hospitalisations, health outcomes and treatment costs in Australia. Injury Prevention. 2018;24(5):344-50.

16. National Centre for Classification in Health ICD-10-AM. Fifth ed. Sydney: National Centre for classification in Health; 2006.

17. Edwards J, Houtrow A, Vasilevskis E, Rehm R, Markovitz B, Graham R, et al. Chronic conditions among children admitted to US pediatric intensive care units: their prevalence and impact on risk for mortality and prolonged length of stay. Crit Care Med. 2012;40(7):2196-203.

18. Mitchell R, Curtis K, Braithwaite J. Health outcomes and costs for injured young people hospitalised with and without chronic health conditions. Injury. 2017
19. Miller C, Shi J, Wheeler K, Yin H, Smith GA, Groner J, et al. Chronic conditions and outcomes of pediatric trauma patients. Journal of Trauma and Acute Care. 2013;75(2):250-7.

20. Stephenson S, Henley G, Harrison J. Langley J. In: Diagnosis-based injury severity scaling Adelaide: Australian Institute of Health and Welfare; 2003.

21. Dayal S, Wren J, Wright C. Mapping injury severity scores against hospitalisation day stays for injury priority areas (excluding workplace injury). Wellington: Public Health Intelligence, Health and Disability Systems Strategy Directorate, Ministry of Health; 2008.

22. Australian Bureau of Statistics Census of Population and Housing: SocioEconomic Indexes for Areas (SEIFA), Australia. Catalogue no: 2033.0.55.001 Canberra: Australian Bureau of Statistics, 2011.

23. SAS Institute. SAS: statistical software. Cary, North Carolina: SAS Institute; 2014.

24. Australian Bureau of Statistics Customised data request - estimated resident population (ERP). Canberra: Australian bureau of Statistics, 2017.

25. Australian Bureau of Statistics. Australian demographic statistics Catalogue No. 3101.0. Which population to use for age standardisation? Canberra: ABS; 2013 [cited 2016 7/3/2016]. Available from: http://www.abs.gov.au/ausstats/ abs@.nsf/products/42479A8EF04E40EBCA257C430016EA3B?OpenDocument.

26. Armitage $P$, Berry $G$, Matthews J. Statistical methods in medical research. Fourth edition ed. Cornwell: Blackwell Science; 2002.

27. Pink B. Socio-Economic Indexes for Areas (SEIFA) 2011. In: Australian Bureau of Statistics, editor. Canberra: Australian Bureau of Statistics, 2013.

28. Laflamme L, Hasselberg M, Burrows S. 20 years of research on socioeconomic inequality and children -unintentional injuries understanding the cause-specific evidence at hand. International Journal of Pediatrics. 2010;2010:23.

29. Peden M, Oyegbite K, Ozanne-Smith J, Hyder A, Branche C, Rahman A, et al. World report on child injury prevention. Geneva, Switzerland: World Health Organization; 2008.

30. Krug E, Sharma G, Lozano R. The global burden of injuries. Am J Public Health. 2000;90:523-6.

31. Hawton K, Harriss L, Hodder K, Simkin S, Gunnell D. The influence of the economic and social environment on deliberate self-harm and suicide: an ecological and person-based study. Psychol Med. 2001;31(5):827-36.

32. Kipping RR, Smith M, Heron J, Hickman M, Campbell R. Multiple risk behaviour in adolescence and socio-economic status: findings from a UK birth cohort. Eur J Pub Health. 2015;25(1):44-9.

33. Gagné M, Hamel D. Deprivation and unintentional injury hospitalization in Quebec children. Chronic Diseases in Canada. 2009;29(2).

34. Groom L, Kendrick D, Coupland C, Patel B, Hippisley-Cox J. Inequalities in hospital admission rates for unintentional poisoning in young children. Injury Prevention. 2006;12(3):166.

35. Reimers A, Laflamme L. Neighbourhood social and socio-economic composition and injury risks. Acta Paediatr. 2005;94(10):1488-94.

36. Schwebel D, Gaines J. Pediatric unintentional injury: behavioral risk factors and implications for prevention. Journal of Developmental \& Behavioral Pediatrics. 2007:28(3):245-54

37. Doswell T, Towner E. Social deprivation and the prevention of unintentional injury in childhood: a systematic review. Health Educ Res. 2002;17(2):221-37.

38. Molnar BE, Goerge RM, Gilsanz P, Hill A, Subramanian SV, Holton JK, et al. Neighborhood-level social processes and substantiated cases of child maltreatment. Child Abuse Negl. 2016;51(Supplement C):41-53.

39. World Health Organization. Socioeconomic differences in injury risks. A review of findings and a discussion of potential countermeasures. Geneva: World Health Organization; 2009.

40. Hosman C. Evidence of effectiveness in mental health promotion In: Lavikainen J, Lahtinen E, Lehtinen V, editors. Proceedings of the European Conference on Promotion of Ment Health Soc Incl Helsinki: Ministry of Social Affairs and Health; 2001.

41. Kendrick D, Smith S, Sutton A, Watson MC, Coupland C, Mulvaney C, et al The effect of education and safety equipment on poisoning prevention practices and poisoning: systematic review, meta-analysis and metaregression. Arch Dis Child. 2008.

42. DiGuiseppi C, Roberts I, Wade A, Sculpher M, Edwards P, Godward C, et al, Incidence of fires and related injuries after giving out free smoke alarms: cluster randomised controlled trial. BMJ. 2002;325(7371):995.

43. Tester JM, Rutherford GW, Wald Z, Rutherford MW. A matched case-control study evaluating the effectiveness of speed humps in reducing child pedestrian injuries. Am J Public Health. 2004;94(4):646-50. 
44. Morgenstern H. Uses of ecological analysis in epidemiological research. Am J Public Health. 1982;72:1336-4.

45. Mustard C, Derksen S, Berthelot JM. M W. assessing ecologic proxies for household income: a comparison of household and neighbourhood level income measures in the study of population health status. Health Place. 1995;5:157-71.

46. Haynes R, Reading R, Gale S. Household and neighbourhood risks for injury to 5-14 year old children. Soc Sci Med. 2003:57:625-36.

Ready to submit your research? Choose BMC and benefit from:

- fast, convenient online submission

- thorough peer review by experienced researchers in your field

- rapid publication on acceptance

- support for research data, including large and complex data types

- gold Open Access which fosters wider collaboration and increased citations

- maximum visibility for your research: over $100 \mathrm{M}$ website views per year

At $\mathrm{BMC}$, research is always in progress.

Learn more biomedcentral.com/submissions 